Published in final edited form as:

Circ Heart Fail. 2014 November ; 7(6): 945-952. doi:10.1161/CIRCHEARTFAILURE.114.001301.

\title{
Calcium-Channel Blockers and Outcomes in Older Patients With Heart Failure and Preserved Ejection Fraction
}

\author{
Kanan Patel, MBBS, MPH ${ }^{1}$, Gregg C. Fonarow, MD ${ }^{2}$, Momanna Ahmed, BGS ${ }^{3}$, Charity \\ Morgan, $\mathrm{PhD}^{3}$, Meredith Kilgore, $\mathrm{PhD}^{3}$, Thomas E. Love, $\mathrm{PhD}^{4}$, Prakash Deedwania, $\mathrm{MD}^{5}$, \\ Wilbert S. Aronow, MD ${ }^{6}$, Stefan D. Anker, MD, PhD ${ }^{7,8}$, and Ali Ahmed, MD, MPH $^{9}$ \\ ${ }^{1}$ University of California, San Francisco, CA \\ ${ }^{2}$ University of California, Los Angeles, CA \\ ${ }^{3}$ University of Alabama at Birmingham, Birmingham, AL \\ ${ }^{4}$ Case Western Reserve University, Cleveland, $\mathrm{OH}$ \\ ${ }^{5}$ University of California, San Francisco, Fresno, CA \\ ${ }^{6}$ New York Medical College, Valhalla, NY \\ ${ }^{7}$ Applied Cachexia Research, Charité, Campus Virchow-Klinikum, Berlin, Germany \\ ${ }^{8}$ Department of Innovative Clinical Trials, University Medical Centre Göttingen, Göttingen, \\ Germany \\ ${ }^{9}$ Veterans Affairs Medical Center, Washington, DC
}

\begin{abstract}
Background-Little is known about associations of calcium channel blockers (CCBs) with outcomes in patients with heart failure and preserved ejection fraction (HFpEF).
\end{abstract}

Methods and Results-Of the 10,570 hospitalized HFpEF patients, $\ 65$ years, EF $\geq 40 \%$, in the Organized Program to Initiate Lifesaving Treatment in Hospitalized Patients with Heart Failure (OPTIMIZE-HF; 2003-2004), linked to Medicare data (through December 31, 2008), 7514 had no prior history of $\mathrm{CCB}$ use. Of these, 815 (11\%) patients received new discharge prescriptions for CCBs. Propensity scores for CCB initiation, calculated for each of the 7514 patients, were used to assemble a matched cohort of 1620 (810 pairs) patients (mean age, 80 years; mean EF, 56\%; 65\% women; 10\% African American) receiving and not receiving CCBs, balanced on 114 baseline characteristics. The primary composite endpoint of all-cause mortality or HF hospitalization occurred in $82 \%$ and $81 \%$ of patients receiving and not receiving CCBs (hazard ratio $\{\mathrm{HR}\}$ for CCBs, 1.03; 95\% confidence interval $\{\mathrm{CI}\}, 0.92-1.14)$. HRs (95\% CIs) for all-cause mortality, HF hospitalization and all-cause hospitalization were 1.05 (0.94-1.18), 1.05 (0.91-1.21), and 1.03 $(0.93-1.14)$, respectively. Similar associations were observed when we categorized patients into

Correspondence to: Ali Ahmed, MD, MPH, Associate Chief of Staff for Health and Aging, Washington DC VA Medical Center, 50 Irving St. NW., Washington, DC 20422, aliahmedmdmph@gmail.com, Telephone: (202)-745-8605, Fax: (202) 745-0000.

Disclosures

None. 
those receiving amlodipine and non-amlodipine CCBs. Among 7514 pre-match patients, multivariable-adjusted and propensity-adjusted HRs $(95 \% \mathrm{CI})$ for primary composite endpoint were $1.03(0.95-1.12)$ and $1.02(0.94-1.11)$, respectively.

Conclusions-In hospitalized older HFpEF patients, new discharge prescriptions for CCBs had no associations with composite or individual endpoints of mortality or HF hospitalization, regardless of the class of CCBs.

\section{Keywords}

calcium channel blocker; heart failure; preserved ejection fraction

Heart failure (HF) is the leading cause for hospital admission and readmission. ${ }^{1,2}$ Nearly half of the estimated 6 million HF patients in the United States have diastolic HF or HF with preserved ejection fraction (HFpEF). ${ }^{1}$ The vast majority of HF patients are $\geq 65$ years, most of who have HFpEF. ${ }^{3}$ However, there is little randomized controlled trial (RCT) evidence to guide therapy for HFpEF patients. ${ }^{4,5}$ Calcium channel blockers (CCBs) have been hypothesized to be beneficial in patients with $\mathrm{HFpEF} .{ }^{4}$ In small studies, CCBs have been shown to improve HF score, exercise capacity, and diastolic function in HFpEF patients. ${ }^{6,7}$ However, the role of CCBs on clinical outcomes in HFpEF patients remains unclear. When RCT data are unavailable or it is impractical or unethical to conduct RCTs, propensity scorematched non-RCT studies based on retrospective outcome-blinded assembly of balanced cohorts may provide evidence in a timely and cost-effective manner. ${ }^{8-11}$ Therefore, in current study, we examined the clinical effectiveness of CCBs in a propensity-matched cohort of older patients with HFpEF.

\section{Methods}

\section{Data Sources and Study Population}

The Organized Program to Initiate Lifesaving Treatment in Hospitalized Patients with Heart Failure (OPTIMIZE-HF) is a national registry of hospitalized HF patients, the rationale and design has been described in detail, previously. ${ }^{12-14}$ Briefly, charts of 48,612 hospitalizations due to HF or associated with HF in 259 hospitals in 48 US states were collected between March 2003 and December 2004. ${ }^{12,13}$ Charts with a primary discharge diagnosis of HF based on International Classification of Diseases, 9th Revision, Clinical Modification (ICD-9-CM) codes were selected regardless of whether a patient was hospitalized for decompensated HF or developed HF symptoms after admission for another admitting diagnosis. Data on baseline demographics, medical history, hospital course, and discharge dispositions were collected in detail. Because HF patients with EF 40\% to 50\% have similar clinical and prognostic characteristics to those with $\mathrm{EF}>50 \%,{ }^{15}$ we used $\mathrm{EF}$ cut off $\geq 40 \%$ to define HFpEF. Of the $48,612 \mathrm{HF}$ hospitalizations, 20,839 occurred in patients with HFpEF.

The OPTIMIZE-HF collected short-term outcome data only for a small subset of patients for 60 to 90 days. To obtain long-term outcome data, we linked OPTIMIZE-HF to Medicare data using 100\% Medicare Provider Analysis and Review (MedPAR) File and 100\% Beneficiary Summary File between January 1, 2002 and December 31, 2008. Of the 20,839 
HFpEF hospitalizations, we were able to link 13,270 hospitalizations to Medicare data that occurred in 11,997 unique patients. Of these, 10,889 were aged $\succeq 65$ years, and 10,570 were discharged alive. ${ }^{16}$ OPTIMIZE-HF was approved by institutional review boards of the participating hospitals.

\section{Assembly of an Eligible Cohort}

Data on admission and discharge use of CCBs and other key HF medications such as angiotensin-converting enzyme inhibitors, angiotensin receptors blockers, aldosterone antagonists, and beta-blockers were collected by chart abstraction. After excluding 146 patients with contraindications to the use of CCBs, such as patients having $2^{\text {nd }}$ or $3^{\text {rd }}$ degree atrioventricular (AV) block ( $\mathrm{n}=33)$, and who had symptomatic hypotension defined as admission systolic blood pressure (BP) $<90 \mathrm{~mm} \mathrm{Hg}(\mathrm{n}=113$ ), the remaining 10,424 patients were considered eligible for CCB therapy.

\section{Assembly of an Inception Cohort}

Because prevalent drug use may cause bias by left censoring or by affecting baseline characteristics, ${ }^{17-19}$ we assembled an inception cohort of patients who were not receiving prior CCB therapy. Therefore, we excluded 2910 patients receiving CCBs during hospital admission. Thus, the final sample size for our inception cohort consisted of 7514 patients, of whom $815(11 \%)$ received a new discharge prescription for CCBs.

\section{Assembly of a Balanced Cohort}

To eliminate the imbalances in measured baseline characteristics due to selection bias associated with a discharge prescription of CCBs, we used propensity score or the probability of receiving a discharge prescription of CCBs to assemble a matched cohort of patients receiving and not receiving $\mathrm{CCBs}$ that would be well balanced on all measured baseline covariates. ${ }^{8-10}$ Using non-parsimonious logistic regression model, we estimated propensity scores for each of the 7514 patients. ${ }^{20-22}$ In this model, the receipt of CCB was the dependent variable and 114 baseline characteristics were used as covariates. Using a greedy matching protocol, we were then able to match 810 of the 815 patients receiving CCBs with another 810 patients not receiving them but had similar propensity to receive it. ${ }^{23,24}$ The effectiveness of propensity score model was assessed by estimating absolute standardized differences, and results were presented as a Love plot (Figure 1). ${ }^{25-27}$ Absolute standardized differences values $<10 \%$ are considered inconsequential and $0 \%$ indicates no residual bias.

\section{Outcomes}

The primary outcome for the current analysis was a composite endpoint of all-cause mortality or HF hospitalization during 6 years of follow-up (median, 2.7 years). Secondary outcomes were all-cause mortality, HF hospitalization, and all-cause hospitalization. As described earlier, all outcomes data were obtained from Medicare claims data. ${ }^{16,} 28$ 


\section{Statistical Analysis}

For descriptive analyses, Pearson's Chi-square and Wilcoxon rank-sum tests were used for pre-match and McNemar's test and paired sample t-test were used for post-match comparisons. Cox proportional hazards regression and Kaplan-Meier analyses were used to determine associations of discharge prescriptions of CCBs with outcomes. Subgroup analyses were conducted to determine homogeneity of associations between CCB use and the primary composite endpoint. A formal sensitivity analysis was planned to estimate the degree of hidden bias that could potentially explain away a significant association among matched patients. ${ }^{29}$ We then repeated our analyses in the pre-match cohort using (1) unadjusted; (2) multivariable-adjusted, using all 114 baseline characteristics; and (3) propensity score-adjusted Cox regression models. We then compared matched patients receiving amlodipine and non-amlodipine CCBs (vs. no CCBs). We repeated an above process to assemble second propensity-matched cohort using EF cutoff 50\%. All statistical tests were two-tailed with a p-value $<0.05$ considered significant. SPSS for Windows version 21 (IBM Corp., Armonk, NY) was used for data analyses.

\section{Results}

\section{Baseline Characteristics}

Matched patients $(n=1620)$ had a mean $( \pm$ SD) age of $80( \pm 8)$ years, mean $( \pm$ SD) left ventricular EF (LVEF) of 56\% ( \pm 9$), 65 \%$ were women and $10 \%$ were African American. Before matching, patients receiving a new prescription for $\mathrm{CCBs}$ were more likely to be younger; African Americans, and had high LVEF and higher prevalence of comorbidities such as hypertension, chronic obstructive pulmonary disease and peripheral vascular disease. They were also less likely to receive angiotensin-converting enzyme inhibitors, betablockers and aldosterone antagonists. These and other pre-match imbalances were balanced after matching (Table 1 and Figure 1). Absolute standardized differences for most of the baseline characteristics between the two treatment groups were $<10 \%$ suggesting substantial bias reduction (Figure 1).

\section{Prescriptions for CCBs and Outcomes}

During six years of follow-up, the primary composite endpoint of all-cause mortality or HF hospitalization occurred in 82\% (666/810) and 81\% (655/810) of matched patients with $\mathrm{HFpEF}$ receiving and not receiving new discharge prescriptions for CCBs, respectively, (hazard ratio $\{\mathrm{HR}\}$ when the use of CCBs was compared with their non-use, 1.03; 95\% confidence interval $\{\mathrm{CI}\}, 0.92-1.14 ; \mathrm{p}=0.638$; Figure 2 and Table 2). Because this association was not statistically significant, a formal sensitivity test was not performed. ${ }^{29}$ The association between CCB prescription and the primary composite endpoint was homogeneous across various subgroups of patients, with the exceptions of African American patients and patients having coronary artery disease (Figure 3). CCB users had no significant association with individual endpoint components of all-cause mortality and hospitalization (Table 2). Similar associations were observed in matched cohorts of HFpEF patients, defined by EF cutoff $50 \%$. 
Among 7514 pre-match patients, HRs (95\% CIs) for unadjusted, multivariable-adjusted and propensity-adjusted associations for primary composite endpoint of all-cause mortality or HF hospitalization with the use of CCBs were 0.96 (0.89-1.04; $\mathrm{p}=0.352), 1.03$ (0.95-1.12; $\mathrm{p}=0.494)$, and $1.02(0.94-1.11 ; \mathrm{p}=0.671$; Table 2$)$, respectively. Similar associations were observed with individual endpoint components of all-cause mortality and hospitalization (Table 2).

\section{Outcomes by CCB Class}

Compared to matched-patients not receiving CCBs, HRs (95\% CIs) for the primary composite endpoint of all-cause mortality or HF hospitalization associated with initiation of amlodipine $(\mathrm{n}=294)$ and non-amlodipine $(\mathrm{n}=510)$ CCBs use were $0.96(0.82-1.11 ; \mathrm{p}=0.543)$ and $1.08(0.96-1.22 ; \mathrm{p}=0.225)$,respectively (Table 3$)$. Corresponding associations for total mortality, HF hospitalization and all-cause hospitalization were displayed in Table 3.

\section{Discussion}

Findings from the current study demonstrate that in a wide spectrum of propensity-matched balanced cohort of older HFpEF patients, a new discharge prescription of CCBs had no association with the primary composite endpoint of all-cause mortality or HF hospitalization or with the secondary individual endpoints of all-cause mortality, HF hospitalization, and all-cause hospitalization. Further, these associations were similar regardless of whether the class of dihydropyridine (amlodipine) or non-dihydropyridine (non-amlodipine) CCB was used. To the best of our knowledge, this is the first report examining clinical effectiveness of $\mathrm{CCBs}$ in a nationally representative real-world population of HFpEF patients using a rigorously-conducted propensity-matched design that provides insights into the role of CCBs in patients with HFpEF.

Hypertension is one of the leading causes of HFpEF in older adults and CCB is one of the commonly prescribed anti-hypertensive drugs. Because there are currently no evidencebased guideline recommendations for the use of CCBs in HFpEF, these drugs were likely used for the control of $\mathrm{BP}$ and heart rate. These findings suggest that the negative inotropic and chronotropic effects of CCBs had no negative association with outcomes in HFpEF. CCBs have been shown to have variable effects on cardiovascular outcomes in $\mathrm{HF}$ patients. ${ }^{30-34}$ In the small placebo-controlled crossover trials of older HFpEF patients, a non-amlodipine CCB, verapamil has been shown to improve exercise capacity, HF score, and LV diastolic function without any significant effect on $\mathrm{BP}$ and EF. ${ }^{6,7}$ Additionally in patients with cardiomyopathy, verapamil and diltiazem had also been shown to significantly improve symptoms by improvements in cardiac function and exercise tolerance. ${ }^{35,36} \mathrm{In}$ animal models, dihydropyridines prevent ischemia-induced increases in LV diastolic stiffness and improve diastolic performance in pacing-induced $\mathrm{HF}^{37}$

According to AHA/ACC HF guidelines, most of the CCBs should be avoided in heart failure and reduced ejection fraction (HFrEF) patients due to its negative inotropic effect and adverse cardiovascular events. ${ }^{4}$ However, in the Prospective Randomized Amlodipine Survival Evaluation (PRAISE) trial, amlodipine had neutral effects on the long-term clinical outcomes in severe chronic HF patients. ${ }^{32}$ Finding from the Survival and Ventricular 
Enlargement (SAVE) trial suggested that in post-myocardial infarction HFrEF patients, nonrandomized use of CCBs had no association with subsequent cardiovascular outcome. ${ }^{33}$ A subgroup analysis of the PRAISE trial, in contrast, demonstrated that amlodipine use was associated with $38 \%$ and $45 \%$ reduced risk of sudden death and pump failure death, respectively, in those with non-ischemic HF. ${ }^{31}$ However, the PRAISE II study demonstrated no improvement in clinical outcomes with amlodipine in patients with non-ischemic HFrEF. $^{38}$ Taken together with findings from RCTs of CCBs in HFrEF, findings from the current study in HFpEF suggest that CCBs do not improve clinical outcomes in HF in general.

Our study has several limitations. We acknowledge that the lack of information about the BP lowering effect of CCBs in our dataset is a limitation. If $\mathrm{BP}$ was lower in the CCB group during follow-up, then the equivalent outcome observed may have occurred despite a differential BP levels as BP has been shown to be associated with outcomes in patients with hypertension, although the association is less well established in patients with HF. ${ }^{14,39,40}$ We had no data on dosages for individual drugs and post-discharge adherence. Substantial crossover during follow-up may result in potential regression dilution and underestimation of true associations, which may in part explain the null association observed in our study. However, findings from other studies suggest that the degree of such post discharge crossover is generally modest and unlikely to completely nullify true associations. ${ }^{41,42} \mathrm{As}$ in any observational study, chance, bias and confounding are potential alternate explanations, but unlikely given the observed null associations. Findings from this study are based on fee-for-service Medicare patients enrolled into OPTIMIZE-HF and may not be generalizable to all Medicare beneficiaries. However, Medicare-linked OPTIMIZE-HF patients have been shown to be characteristically and prognostically similar to HF patients in the general Medicare population. ${ }^{28}$ Finally, the data for this study were collected from medical records and depended on the accuracy and completeness of clinical documentation.

In conclusion, in real-world hospitalized older HFpEF patients not receiving prior CCBs, a new discharge prescription for CCBs had no associations with the primary composite endpoint of total mortality or HF hospitalization and individual endpoints of mortality or hospitalization, regardless of the class of CCBs.

\section{Supplementary Material}

Refer to Web version on PubMed Central for supplementary material.

\section{Acknowledgments}

Sources of Funding

Ali Ahmed was supported by the NIH through grant (R01-HL097047) from the NHLBI, and a generous gift from Ms. Jean B. Morris of Birmingham, AL. OPTIMIZE-HF was funded by GlaxoSmithKline (PI: Gregg C. Fonarow).

\section{References}

1. Roger VL, Go AS, Lloyd-Jones DM, Benjamin EJ, Berry JD, Borden WB, Bravata DM, Dai S, Ford ES, Fox CS, Fullerton HJ, Gillespie C, Hailpern SM, Heit JA, Howard VJ, Kissela BM, Kittner SJ, Lackland DT, Lichtman JH, Lisabeth LD, Makuc DM, Marcus GM, Marelli A, Matchar DB, Moy 
CS, Mozaffarian D, Mussolino ME, Nichol G, Paynter NP, Soliman EZ, Sorlie PD, Sotoodehnia N, Turan TN, Virani SS, Wong ND, Woo D, Turner MB, American Heart Association Statistics C, Stroke Statistics S. Heart disease and stroke statistics-2012 update: A report from the american heart association. Circulation. 2012; 125:e2-e220. [PubMed: 22179539]

2. Jencks SF, Williams MV, Coleman EA. Rehospitalizations among patients in the medicare fee-forservice program. N Engl J Med. 2009; 360:1418-1428. [PubMed: 19339721]

3. Kitzman DW, Gardin JM, Gottdiener JS, Arnold A, Boineau R, Aurigemma G, Marino EK, Lyles M, Cushman M, Enright PL, Cardiovascular Health Study Research G. Importance of heart failure with preserved systolic function in patients $>$ or $=65$ years of age. Chs research group. Cardiovascular health study. Am J Cardiol. 2001; 87:413-419. [PubMed: 11179524]

4. Hunt SA, Abraham WT, Chin MH, Feldman AM, Francis GS, Ganiats TG, Jessup M, Konstam MA, Mancini DM, Michl K, Oates JA, Rahko PS, Silver MA, Stevenson LW, Yancy CW. 2009 focused update incorporated into the acc/aha 2005 guidelines for the diagnosis and management of heart failure in adults: A report of the american college of cardiology foundation/american heart association task force on practice guidelines: Developed in collaboration with the international society for heart and lung transplantation. Circulation. 2009; 119:e391-e479. [PubMed: 19324966]

5. Oghlakian GO, Sipahi I, Fang JC. Treatment of heart failure with preserved ejection fraction: Have we been pursuing the wrong paradigm? Mayo Clin Proc. 2011; 86:531-539. [PubMed: 21576513]

6. Hung MJ, Cherng WJ, Kuo LT, Wang CH. Effect of verapamil in elderly patients with left ventricular diastolic dysfunction as a cause of congestive heart failure. Int J Clin Pract. 2002; 56:5762. [PubMed: 11831838]

7. Setaro JF, Zaret BL, Schulman DS, Black HR, Soufer R. Usefulness of verapamil for congestive heart failure associated with abnormal left ventricular diastolic filling and normal left ventricular systolic performance. Am J Cardiol. 1990; 66:981-986. [PubMed: 2220622]

8. Rosenbaum PR, Rubin DB. The central role of propensity score in observational studies for causal effects. Biometrika. 1983; 70:41-55.

9. Rubin DB. Using propensity score to help design observational studies: Application to the tobacco litigation. Health Services and Outcomes Research Methodology. 2001; 2:169-188.

10. Austin PC. Primer on statistical interpretation or methods report card on propensity-score matching in the cardiology literature from 2004 to 2006: A systematic review. Circ Cardiovasc Qual Outcomes. 2008; 1:62-67. [PubMed: 20031790]

11. Michels KB, Braunwald E. Estimating treatment effects from observational data: Dissonant and resonant notes from the symphony trials. JAMA. 2002; 287:3130-3132. [PubMed: 12069677]

12. Fonarow GC, Abraham WT, Albert NM, Gattis WA, Gheorghiade M, Greenberg B, O'Connor CM, Yancy CW, Young J. Organized program to initiate lifesaving treatment in hospitalized patients with heart failure (optimize-hf): Rationale and design. Am Heart J. 2004; 148:43-51. [PubMed: 15215791]

13. Fonarow GC, Abraham WT, Albert NM, Stough WG, Gheorghiade M, Greenberg BH, O'Connor CM, Pieper K, Sun JL, Yancy C, Young JB. Association between performance measures and clinical outcomes for patients hospitalized with heart failure. JAMA. 2007; 297:61-70. [PubMed: 17200476]

14. Gheorghiade M, Abraham WT, Albert NM, Greenberg BH, O'Connor CM, She LL, Stough WG, Yancy CW, Young JB, Fonarow GC. Systolic blood pressure at admission, clinical characteristics, and outcomes in patients hospitalized with acute heart failure. JAMA. 2006; 296:2217-2226. [PubMed: 17090768]

15. Fonarow GC, Stough WG, Abraham WT, Albert NM, Gheorghiade M, Greenberg BH, O'Connor CM, Sun JL, Yancy CW, Young JB. Investigators O-H, Hospitals. Characteristics, treatments, and outcomes of patients with preserved systolic function hospitalized for heart failure: A report from the optimize-hf registry. J Am Coll Cardiol. 2007; 50:768-777. [PubMed: 17707182]

16. Zhang Y, Kilgore ML, Arora T, Mujib M, Ekundayo OJ, Aban IB, Feller MA, Desai RV, Love TE, Allman RM, Fonarow GC, Ahmed A. Design and rationale of studies of neurohormonal blockade and outcomes in diastolic heart failure using optimize-hf registry linked to medicare data. Int J Cardiol. 2013; 166:230-235. [PubMed: 22119116] 
17. Ray WA. Evaluating medication effects outside of clinical trials: New-user designs. Am J Epidemiol. 2003; 158:915-920. [PubMed: 14585769]

18. Hernan MA, Hernandez-Diaz S, Robins JM. A structural approach to selection bias. Epidemiology. 2004; 15:615-625. [PubMed: 15308962]

19. Danaei G, Tavakkoli M, Hernan MA. Bias in observational studies of prevalent users: Lessons for comparative effectiveness research from a meta-analysis of statins. Am J Epidemiol. 2012; 175:250-262. [PubMed: 22223710]

20. Patel K, Fonarow GC, Kitzman DW, Aban IB, Love TE, Allman RM, Gheorghiade M, Ahmed A. Angiotensin receptor blockers and outcomes in real-world older patients with heart failure and preserved ejection fraction: A propensity-matched inception cohort clinical effectiveness study. Eur J Heart Fail. 2012; 14:1179-1188. [PubMed: 22759445]

21. Deedwania PC, Ahmed MI, Feller MA, Aban IB, Love TE, Pitt B, Ahmed A. Impact of diabetes mellitus on outcomes in patients with acute myocardial infarction and systolic heart failure. Eur $\mathbf{J}$ Heart Fail. 2011; 13:551-559. [PubMed: 21393298]

22. Filippatos GS, Ahmed MI, Gladden JD, Mujib M, Aban IB, Love TE, Sanders PW, Pitt B, Anker $\mathrm{SD}$, Ahmed A. Hyperuricaemia, chronic kidney disease, and outcomes in heart failure: Potential mechanistic insights from epidemiological data. Eur Heart J. 2011; 32:712-720. [PubMed: 21199831]

23. Patel K, Fonarow GC, Kitzman DW, Aban IB, Love TE, Allman RM, Gheorghiade M, Ahmed A. Aldosterone antagonists and outcomes in real-world older patients with heart failure and preserved ejection fraction. JACC Heart Fail. 2013; 1:40-47. [PubMed: 23814702]

24. Ahmed A, Fonarow GC, Zhang Y, Sanders PW, Allman RM, Arnett DK, Feller MA, Love TE, Aban IB, Levesque R, Ekundayo OJ, Dell'Italia LJ, Bakris GL, Rich MW. Renin-angiotensin inhibition in systolic heart failure and chronic kidney disease. Am J Med. 2012; 125:399-410. [PubMed: 22321760]

25. Ahmed A, Perry GJ, Fleg JL, Love TE, Goff DC Jr, Kitzman DW. Outcomes in ambulatory chronic systolic and diastolic heart failure: A propensity score analysis. Am Heart J. 2006; 152:956-966. [PubMed: 17070167]

26. Ahmed MI, White M, Ekundayo OJ, Love TE, Aban I, Liu B, Aronow WS, Ahmed A. A history of atrial fibrillation and outcomes in chronic advanced systolic heart failure: A propensity-matched study. Eur Heart J. 2009; 30:2029-2037. [PubMed: 19531579]

27. Guichard JL, Desai RV, Ahmed MI, Mujib M, Fonarow GC, Feller MA, Ekundayo OJ, Bittner V, Aban IB, White M, Aronow WS, Love TE, Bakris GL, Zieman SJ, Ahmed A. Isolated diastolic hypotension and incident heart failure in older adults. Hypertension. 2011; 58:895-901. [PubMed: 21947466]

28. Curtis LH, Greiner MA, Hammill BG, DiMartino LD, Shea AM, Hernandez AF, Fonarow GC. Representativeness of a national heart failure quality-of-care registry: Comparison of optimize-hf and non-optimize-hf medicare patients. Circ Cardiovasc Qual Outcomes. 2009; 2:377-384. [PubMed: 20031864]

29. Rosenbaum, PR. Sensitivity to hidden bias. In: Rosenbaum, PR., editor. Observational studies. New York: Springer-Verlag; 2002. p. 105-170.

30. Costanzo P, Perrone-Filardi P, Petretta M, Marciano C, Vassallo E, Gargiulo P, Paolillo S, Petretta A, Chiariello M. Calcium channel blockers and cardiovascular outcomes: A meta-analysis of 175,634 patients. J Hypertens. 2009; 27:1136-1151. [PubMed: 19451836]

31. O'Connor CM, Carson PE, Miller AB, Pressler ML, Belkin RN, Neuberg GW, Frid DJ, Cropp AB, Anderson S, Wertheimer JH, DeMets DL. Effect of amlodipine on mode of death among patients with advanced heart failure in the praise trial. Prospective randomized amlodipine survival evaluation. Am J Cardiol. 1998; 82:881-887. [PubMed: 9781971]

32. Packer M, O'Connor CM, Ghali JK, Pressler ML, Carson PE, Belkin RN, Miller AB, Neuberg GW, Frid D, Wertheimer JH, Cropp AB, DeMets DL. Effect of amlodipine on morbidity and mortality in severe chronic heart failure. Prospective randomized amlodipine survival evaluation study group. N Engl J Med. 1996; 335:1107-1114. [PubMed: 8813041]

33. Hager WD, Davis BR, Riba A, Moye LA, Wun CC, Rouleau JL, Lamas GA, Pfeffer MA. Absence of a deleterious effect of calcium channel blockers in patients with left ventricular dysfunction 
after myocardial infarction: The save study experience. Save investigators. Survival and ventricular enlargement. Am Heart J. 1998; 135:406-413. [PubMed: 9506325]

34. Cleophas TJ, van Marum R. Meta-analysis of efficacy and safety of second-generation dihydropyridine calcium channel blockers in heart failure. Am J Cardiol. 2001; 87:487-490. A487-A488. [PubMed: 11179544]

35. Bonow RO, Dilsizian V, Rosing DR, Maron BJ, Bacharach SL, Green MV. Verapamil-induced improvement in left ventricular diastolic filling and increased exercise tolerance in patients with hypertrophic cardiomyopathy: Short- and long-term effects. Circulation. 1985; 72:853-864. [PubMed: 4040821]

36. Figulla HR, Gietzen F, Zeymer U, Raiber M, Hegselmann J, Soballa R, Hilgers R. Diltiazem improves cardiac function and exercise capacity in patients with idiopathic dilated cardiomyopathy. Results of the diltiazem in dilated cardiomyopathy trial. Circulation. 1996; 94:346-352. [PubMed: 8759075]

37. Cheng CP, Pettersson K, Little WC. Effects of felodipine on left ventricular systolic and diastolic performance in congestive heart failure. J Pharmacol Exp Ther. 1994; 271:1409-1417. [PubMed: 7996453]

38. Packer M, Carson PE, Elkayam U, Konstam MA, Moe G, O'Connor C, Rouleau J, Schocken D, Anderson SA, DeMets DL. Effect of amlodipine on the survival of patients with severe chronic heart failure due to a nonischemic cardiomyopathy: Results of the praise-2 study (prospective randomized amlodipine survival evaluation 2). J Am Coll Cardiol HF. 2013; 1:308-314.

39. Banach M, Bhatia V, Feller MA, Mujib M, Desai RV, Ahmed MI, Guichard JL, Aban I, Love TE, Aronow WS, White M, Deedwania P, Fonarow G, Ahmed A. Relation of baseline systolic blood pressure and long-term outcomes in ambulatory patients with chronic mild to moderate heart failure. Am J Cardiol. 2011; 107:1208-1214. [PubMed: 21296319]

40. Desai RV, Banach M, Ahmed MI, Mujib M, Aban I, Love TE, White M, Fonarow G, Deedwania P, Aronow WS, Ahmed A. Impact of baseline systolic blood pressure on long-term outcomes in patients with advanced chronic systolic heart failure (insights from the best trial). Am J Cardiol. 2010; 106:221-227. [PubMed: 20599007]

41. Butler J, Arbogast PG, Daugherty J, Jain MK, Ray WA, Griffin MR. Outpatient utilization of angiotensin-converting enzyme inhibitors among heart failure patients after hospital discharge. $\mathrm{J}$ Am Coll Cardiol. 2004; 43:2036-2043. [PubMed: 15172409]

42. Curtis LH, Mi X, Qualls LG, Check DK, Hammill BG, Hammill SC, Heidenreich PA, Masoudi FA, Setoguchi S, Hernandez AF, Fonarow GC. Transitional adherence and persistence in the use of aldosterone antagonist therapy in patients with heart failure. Am Heart J. 2013; 165:979-986. e971. [PubMed: 23708170] 


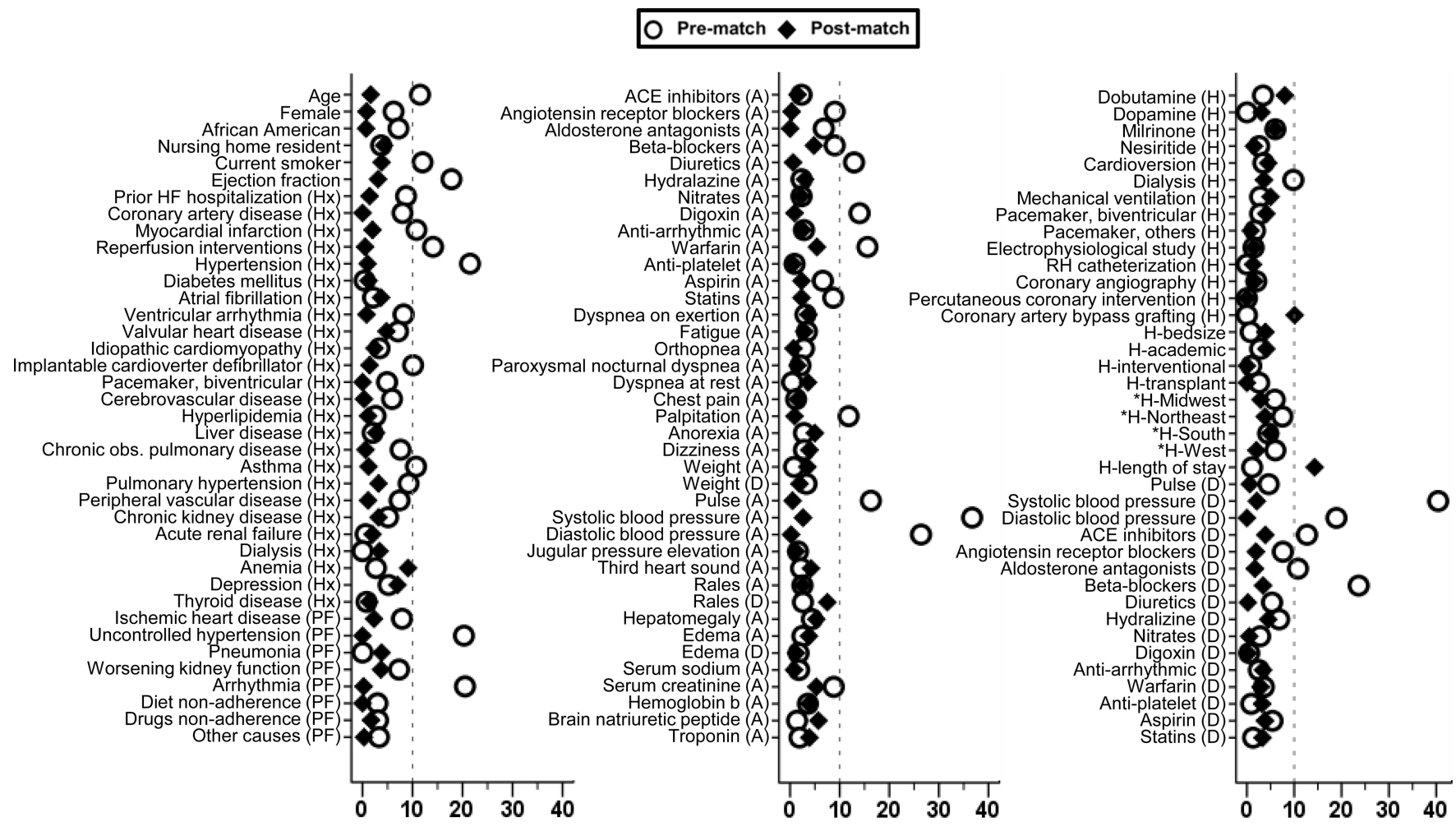

Absolute standardized difference (\%)

Figure 1.

Love plot displaying absolute standardized differences comparing 114 baseline characteristics between older patients with heart failure and preserved ejection fraction, receiving a new discharge prescription of calcium channel blockers, before and after propensity score matching $(\mathrm{Hx}=$ past medical history, $\mathrm{A}=$ admission, $\mathrm{D}=$ discharge, $\mathrm{H}=\mathrm{in}$ hospital, $\mathrm{PF}=$ precipitating factor, $\mathrm{ACE}=$ angiotensin-converting enzyme, $* 4$ regions entered as single categorical variable in the model) 


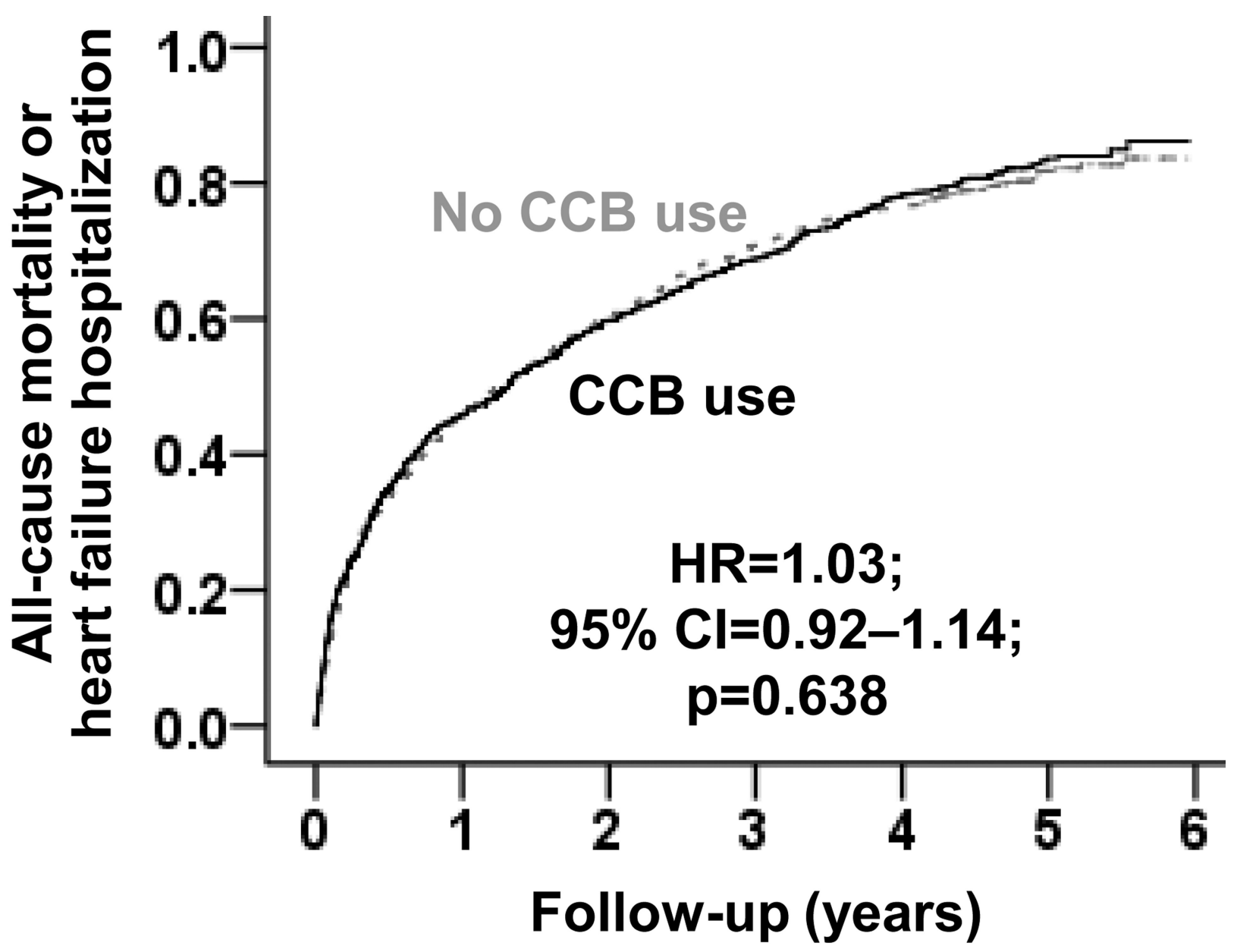

No. at risk

$\begin{array}{lllllll}\text { No CCB use } & 810 & 440 & 321 & 236 & 191 & 56\end{array}$

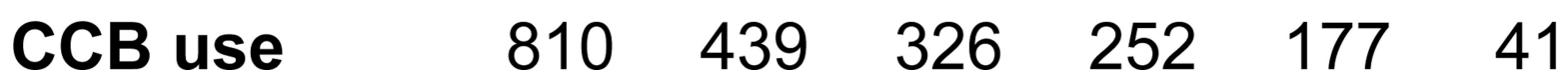

Figure 2.

Kaplan-Meier plot for primary composite endpoint of all-cause mortality or heart failure hospitalization in a propensity-matched inception cohort of older patients with heart failure and preserved ejection fraction, receiving and not receiving a new discharge prescription for calcium channel blockers $(\mathrm{CCB})(\mathrm{HR}=$ hazard ratio, $\mathrm{CI}=$ confidence interval) 


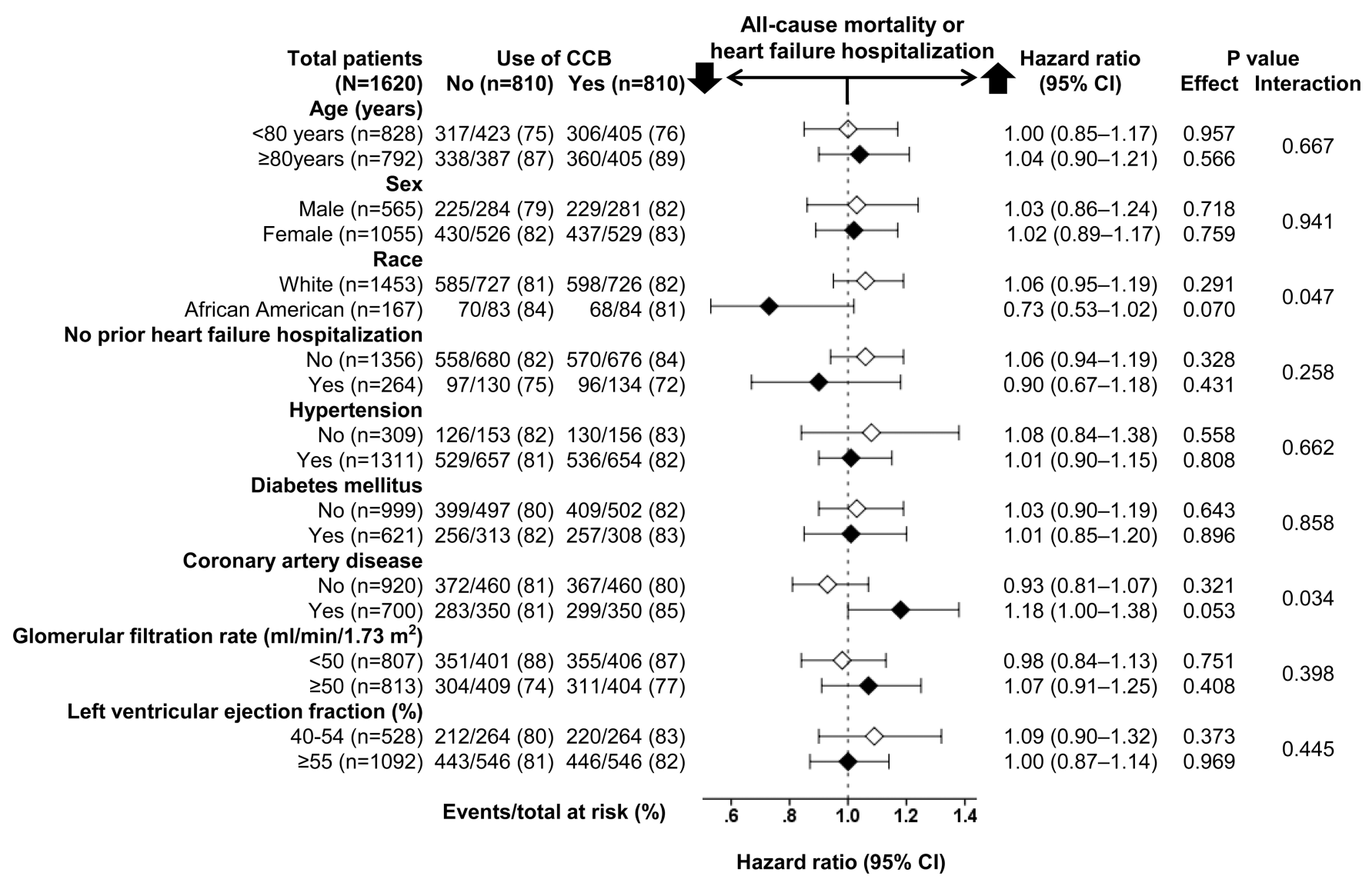

Figure 3.

Association of a new discharge prescription for calcium channel blockers (CCB) with primary composite endpoint of all-cause mortality or heart failure hospitalization in subgroups of propensity-matched inception cohort of older patients with heart failure and preserved ejection fraction 


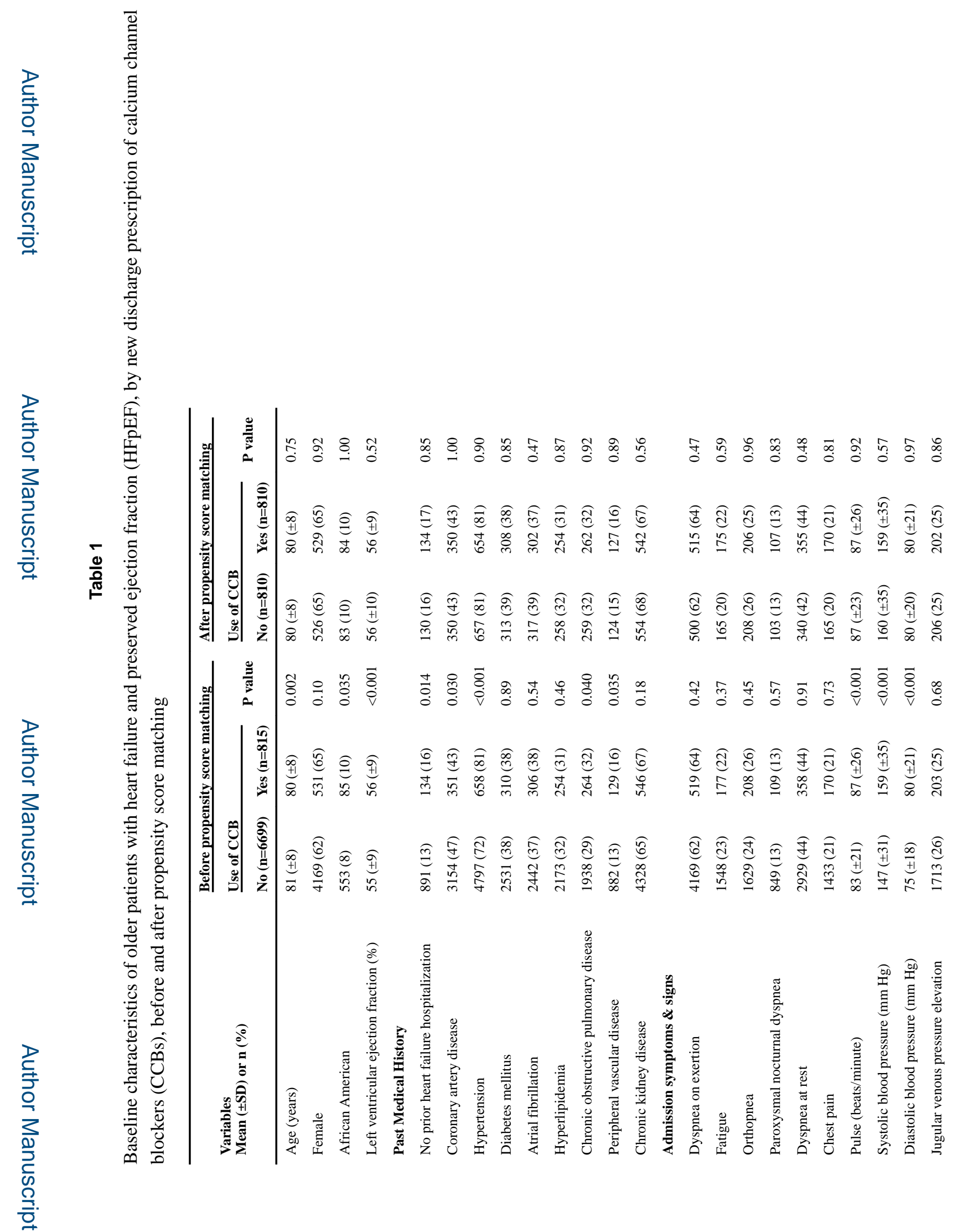

Circ Heart Fail. Author manuscript; available in PMC 2016 August 25. 
Patel et al.

Page 14

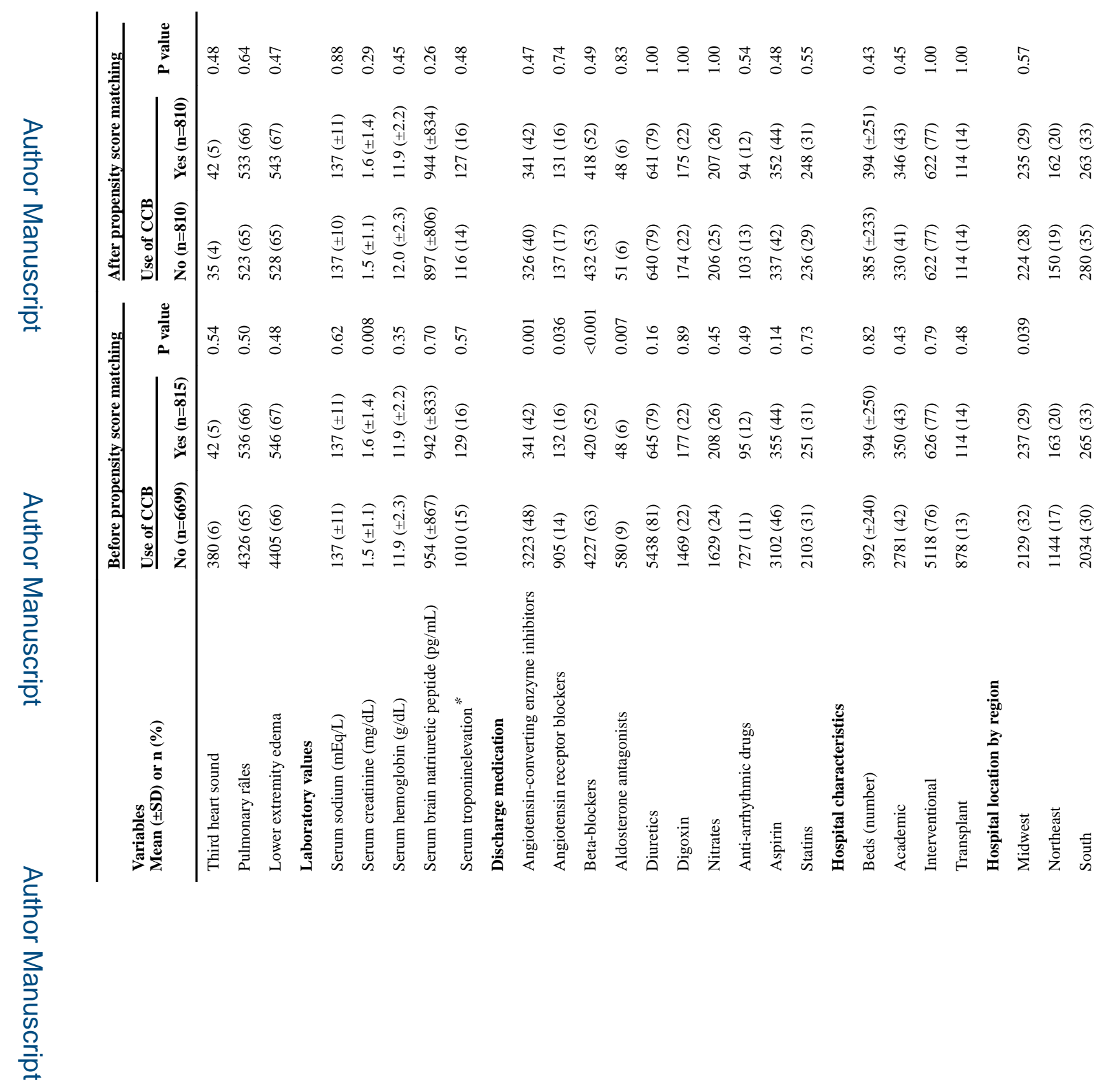

로을

Circ Heart Fail. Author manuscript; available in PMC 2016 August 25. 
Patel et al.

Page 15

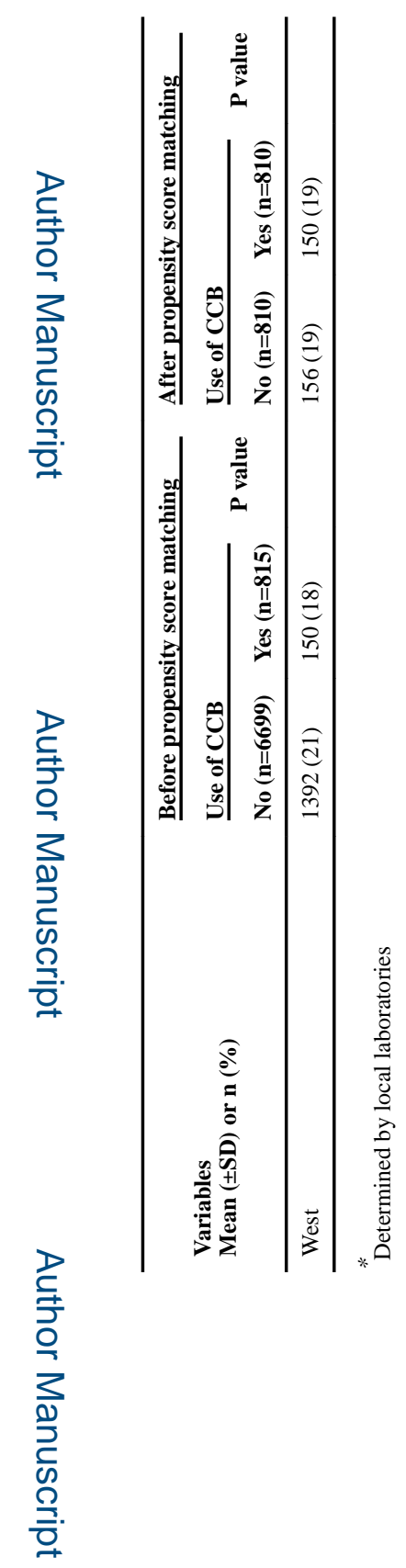

로을

Circ Heart Fail. Author manuscript; available in PMC 2016 August 25. 


\section{Table 2}

Association of a new discharge prescription of calcium channel blockers (CCBs) with outcomes in inception cohort of hospitalized older patients with heart failure and preserved ejection fraction (HFpEF)

\begin{tabular}{|c|c|c|c|c|}
\hline \multirow{3}{*}{ Outcomes } & \multicolumn{2}{|c|}{$\%$ (events/total at risk) } & \multirow{3}{*}{$\begin{array}{l}\text { Hazard ratio* }(95 \% \\
\text { CI) }\end{array}$} & \multirow{3}{*}{$P$ value } \\
\hline & \multicolumn{2}{|l|}{ Use of CCBs } & & \\
\hline & No & Yes & & \\
\hline \multicolumn{5}{|l|}{$\begin{array}{l}\text { All-cause mortality or HF } \\
\text { hospitalization }\end{array}$} \\
\hline Pre-match unadjusted & $83 \%(5547 / 6699)$ & $82 \%(671 / 815)$ & $0.96(0.89-1.04)$ & 0.35 \\
\hline Multivariable-adjusted $^{\dagger}$ & & & $1.03(0.95-1.12)$ & 0.49 \\
\hline Propensity score-adjusted ${ }^{*}$ & & & $1.02(0.94-1.11)$ & 0.67 \\
\hline Propensity-matched & $81 \%(655 / 810)$ & $82 \%(666 / 810)$ & $1.03(0.92-1.14)$ & 0.64 \\
\hline \multicolumn{5}{|l|}{ All-cause mortality } \\
\hline Pre-match unadjusted & $72 \%(4789 / 6699)$ & $70 \%(574 / 815)$ & $0.94(0.87-1.03)$ & 0.19 \\
\hline Multivariable-adjusted ${ }^{\dagger}$ & & & $1.03(0.94-1.13)$ & 0.55 \\
\hline Propensity score-adjusted $t$ & & & $1.00(0.92-1.10)$ & 0.95 \\
\hline Propensity-matched & $68 \%(550 / 810)$ & $70 \%(569 / 810)$ & $1.05(0.94-1.18)$ & 0.39 \\
\hline \multicolumn{5}{|l|}{ HF hospitalization } \\
\hline Pre-match unadjusted & $44 \%(2955 / 6699)$ & $45 \%(369 / 815)$ & $1.00(0.89-1.11)$ & 0.94 \\
\hline Multivariable-adjusted ${ }^{\dagger}$ & & & $1.06(0.94-1.18)$ & 0.35 \\
\hline Propensity score-adjusted $\neq$ & & & $1.06(0.95-1.19)$ & 0.30 \\
\hline Propensity-matched & $44 \%(353 / 810)$ & $45 \%(367 / 810)$ & $1.05(0.91-1.21)$ & 0.53 \\
\hline \multicolumn{5}{|l|}{ All-cause hospitalization } \\
\hline Pre-match unadjusted & $87 \%(5800 / 6699)$ & $88 \%(713 / 815)$ & $1.00(0.93-1.09)$ & 0.93 \\
\hline Multivariable-adjusted $^{\dagger}$ & & & $1.03(0.95-1.12)$ & 0.50 \\
\hline Propensity score-adjusted ${ }^{*}$ & & & $1.02(0.94-1.11)$ & 0.58 \\
\hline Propensity-matched & $89 \%(719 / 810)$ & $87 \%(708 / 810)$ & $1.03(0.93-1.14)$ & 0.61 \\
\hline
\end{tabular}




\section{Table 3}

Association of a new discharge prescription of calcium channel blockers (CCBs) with outcomes in propensitymatched inception cohort of hospitalized older patients with heart failure and preserved ejection fraction (HFpEF), by a class of CCBs

\begin{tabular}{|c|c|c|c|c|}
\hline \multirow{3}{*}{ Outcomes } & \multicolumn{2}{|l|}{ \% (events) } & \multirow{3}{*}{ Hazard ratio $^{*}(95 \% \mathrm{CI})$} & \multirow{3}{*}{ P value } \\
\hline & \multicolumn{2}{|c|}{ Use of CCBs } & & \\
\hline & No & Yes & & \\
\hline Amlodipine & $(\mathrm{n}=\mathbf{8 1 0})$ & $(\mathrm{n}=294)^{\dagger}$ & & \\
\hline All-cause mortality or HF hospitalization & $81 \%(655)$ & $81 \%(239)$ & $0.96(0.82-1.11)$ & 0.54 \\
\hline All-cause mortality & $68 \%(550)$ & $66 \%(193)$ & $0.92(0.78-1.09)$ & 0.34 \\
\hline HF hospitalization & $44 \%(353)$ & $47 \%(139)$ & $1.03(0.85-1.26)$ & 0.74 \\
\hline All-cause hospitalization & $89 \%(719)$ & $89 \%(261)$ & $0.99(0.86-1.14)$ & 0.87 \\
\hline Non-amlodipine & $(\mathrm{n}=\mathbf{8 1 0})$ & $(\mathbf{n}=\mathbf{5 1 0})^{\dagger}$ & & \\
\hline All-cause mortality or HF hospitalization & $81 \%(655)$ & $83 \%(424)$ & $1.08(0.96-1.22)$ & 0.23 \\
\hline All-cause mortality & $68 \%(550)$ & $73 \%(373)$ & $1.14(1.00-1.30)$ & 0.048 \\
\hline HF hospitalization & $44 \%(353)$ & $44 \%(226)$ & $1.06(0.90-1.26)$ & 0.47 \\
\hline All-cause hospitalization & $89 \%(719)$ & $87 \%(442)$ & $1.06(0.94-1.19)$ & 0.37 \\
\hline
\end{tabular}

